\title{
A RETROSPECTIVE STUDY OF DISTAL RADIUS FRACTURES TREATED BY CONSERVATIVE METHOD
}

\author{
Ch. V. Murali Krishna ${ }^{1}$, P. Ashok Kumar², S. Sankara Rao 3 , K. Srinivasarao ${ }^{4}$, P. Varun Kumar 5 , P. Rambabu 6 , K. Sudhakar , \\ V. V. Satyanarayana ${ }^{8}$
}

${ }^{1}$ Assistant Professor, Department of Orthopaedics, King George Hospital, Andhra Medical College, Visakhapatnam, Andhra Pradesh. ${ }^{2}$ Professor I/c, Department of Orthopaedics, King George Hospital, Andhra Medical College, Visakhapatnam, Andhra Pradesh. ${ }^{3}$ Assistant Professor, Department of Orthopaedics, King George Hospital, Andhra Medical College, Visakhapatnam, Andhra Pradesh. ${ }^{4}$ Assistant Professor, Department of Orthopaedics, King George Hospital, Andhra Medical College, Visakhapatnam, Andhra Pradesh. ${ }^{5}$ Senior Resident, Department of Orthopaedics, King George Hospital, Andhra Medical College, Visakhapatnam, Andhra Pradesh. ${ }^{6}$ AssistantProfessor, Department of Orthopaedics, King George Hospital, Andhra Medical College, Visakhapatnam, Andhra Pradesh. 7Junior Resident, Department of Orthopaedics, King George Hospital, Andhra Medical College, Visakhapatnam, Andhra Pradesh. 8Junior Resident,, Department of Orthopaedics, King George Hospital, Andhra Medical College, Visakhapatnam, Andhra Pradesh.

ABSTRACT: BACKGROUND: Undisplaced and minimally displaced fractures of the distal radius are one of the most common injuries. The conservative management of these fractures with closed manipulative reduction and Plaster of Paris casting and assessment of the functional results and complications is the aim of this study.

MATERIALS \& METHODS: One hundred cases of distal radius fractures in patients aged above 40 years who attended the orthopaedic OPD at King George Hospital, Visakhapatnam from September 2010 to August 2012 were studied retrospectively for a period of 2 years. Only extra articular distal radius fractures treated by closed manipulation and pop cast immobilization were included in this study. POP cast was removed at 6 weeks and patients were sent for rehabilitation to physiotherapy department. All Patients were functionally assessed at regular intervals for a period of 3 months.

RESULTS: Functional evaluation was done based on Demerit point system of Gartland \& Werley with Sarmiento et al modification. $12 \%$ of the patients had excellent outcome, $39 \%$ good results, $41 \%$ had fair outcome and $8 \%$ poor results.

CONCLUSION: Better results were achieved in undisplaced and minimally displaced fractures treated conservatively by closed manipulative reduction and cast immobilization. However as the degree of displacement increases the results obtained were poor. Gross displacement and communition were associated with poor results even though accurate reduction was obtained during manipulation. Hence it may be concluded that conservative management still holds good for undisplaced and minimally displaced fractures, however in fractures of distal radius with significant displacement and comminution especially if the quality of bone is not good, it is difficult to obtain good functional outcome through conservative management alone.

KEYWORDS: Colles Fracture, Extra Articular Conservative Management.

HOW TO CITE THIS ARTICLE:Ch. V. Murali Krishna, P. Ashok Kumar, S. Sankara Rao, K. Srinivasarao, P. Varun Kumar, P. Rambabu, K. Sudhakar, V. V. Satyanarayana. "A Retrospective Study of Distal Radius Fractures Treated by Conservative Method". Journal of Evolution of Medical and Dental Sciences 2015; Vol. 4, Issue 92, November 16; Page: 15791-15797,

DOI: $10.14260 /$ jemds/2015/2283.

INTRODUCTION: Fractures of the distal radius are the most common fractures of the upper extremity and account for $74 \%$ of all forearm fractures and $1 / 6^{\text {th }}$ of all fractures treated in the emergency department; $50 \%$ involve the radiocarpal or radioulnar joints. They occur in bi-modal distribution; younger patients have high-energy injuries and older patients have injuries associated with falls. They are likely to increase due to a rising number of elderly people.

Initially thought to be simple fractures, they are now recognized as complex injuries with a high percentage of long term complications. No fracture in the body is as ubiquitous and fraught with potential complications as the distal radius fracture. Malunion and post-traumatic arthritis are the two

Financial or Other, Competing Interest: None.

Submission 20-10-2015, Peer Review 21-10-2015,

Acceptance 06-11-2015, Published 16-11-2015.

Corresponding Author:

Dr. P. Ashok Kumar,

Department of Orthopaedics,

Do. No. B-98, Dayal Nagar,

Visakhapatnam-530043, Andhra Pradesh.

E-mail: ashok_ortho59@rediffmail.com

DOI:10.14260/jemds/2015/2283. most common complications following conservative management. Malunion leads to detrimental alterations in radiocarpal, ulnocarpal and distal radioulnar joint mechanics with serious functional impairment.

The result leaves behind considerable homework for the recovering patients and a permanent blemish to the reputation of the treating surgeon.

Preservation of articular congruity is the principal prerequisite for successful recovery following distal radius fractures. Adding to the problem, comminuted intra-articular fractures of distal radius are notorious for irreducibility and instability. Various methods of treatment adopted may be considered as testimony to the apparent dissatisfaction with any single technique. The best method of obtaining and maintaining an accurate restoration of articular anatomy, however, remains a topic of considerable controversy.

Unstable intra articular fractures of distal radius remain a challenging problem. If these fractures are allowed to collapse, which results in radial shortening, angulation, and articular incongruity, may cause permanent deformity and loss of function. 
The management of fractures of the distal radius has undergone an extraordinary evolution over the preceding twenty years. Although some patients still seem to confirm Abraham Colles' famous remarks that the casted wrist "Will at some remote period again enjoy perfect freedom in all of its motions and be completely exempt from pain,". ${ }^{1}$ It remains a mystery as to why the management of the complex group of fractures of the distal radius is still so often directed by a statement made by Abraham Colles over 190 years ago (1814) (Joseph Schatzker). ${ }^{2}$

The incidence of this injury appears to be both gender and age specific.[3] An increasing preponderance of published studies support the need for operative intervention in this aging population. There seems to be a growing incidence of these fractures in all three groups, with the sharpest increase seen in both elderly females and younger adult males.[4] With an aging society with greater longevity, previously held dictums of cast treatment for geriatric patients are being challenged both by surgeons and the society. Finally, and perhaps most importantly, it is becoming increasingly apparent that operative intervention needs to be customized to the patient and the fracture as well as the expertise of the surgeon.

AIM OF THE STUDY: An evaluation of functional outcome of conservative management of Distal radius fractures by closed manipulative reduction and cast immobilization in 100 patients, aged above 40 years of age, presenting to the Orthopaedics outpatient department of King George Hospital between September 2010-August 2012, was performed.

\section{The aim of the study was:}

1. To evaluate the functional outcome of Distal radius fractures following conservativemanagement by closed manipulative reduction and cast immobilization.

2. To analyse the various factors that influence the outcome of conservativemanagement.

3. To study the limitations of daily activities which arise following conservativemanagement.

4. To study the complications that might arise following conservative management.

OBJECTIVES: This study was undertaken in the Department of Orthopaedics, King George Hospital, Visakhapatnam, during the period, September 2010 to August 2012. During this period we have treated extra articular distal radius fractures by closed manipulative reduction and cast immobilization.

The main objective of this study is to evaluate, the effectiveness of conservative management, a treatment modality which was proposed way back in old times. This study is an attempt to understand whether conservative management still holds good in $21^{\text {st }}$ century when surgery has overtaken most of the conservative modes of treatment even now.

This study also tries to analyse the various complications that might arise following conservative management and identify the factors that influence the outcome.

This study has been done to evaluate the results (In terms of functional outcome) of distal radius fractures following conservative management which involves closed manipulative reduction and cast immobilization.

MATERIALS AND METHODS: One hundred cases of distal radius fractures in patients aged above 40 years who attended the orthopaedic OP, King George Hospital, Visakhapatnam for a period of 2 years i.e., from September 2010 to August 2012 were studied retrospectively.

Extra articular fractures of distal radius which are categorized under A0 classification 23 A ( 2 \& 3 ) were included in the study.

Inclusion Criteria: All patients with distal radius fracture with the following characteristics were included in this study.

1. Age more than 40 years.

2. Extra articular type of distal radius fractures.

3. Stable fractures.

4. Angular deformity $<10^{\circ}$, shortening $<5 \mathrm{~mm}$ Articular, displacement $<2 \mathrm{~mm}$.

5. Patients in whom operative treatment is contraindicated due to co-morbid conditions.

Exclusion Criteria: Patients with distal radius fractures but, with the following characteristics were excluded from the study.

1. Patients aged below 40 years.

2. Intra articular type of distal radius fractures.

3. Open \& bilateral Colles' fracture.

4. Associated Ipsilateral scaphoid \& forearm fractures.

5. Significant radiocarpal instability.

6. Angular deformity $>10^{\circ}$, shortening $>5 \mathrm{~mm}$, articular displacement $>2 \mathrm{~mm}$.

After initial evaluation of the general condition, closed manipulative reduction of the fracture was performed under General Anaesthesia/Brachial Block. Reduction of the fracture was checked under C ARM. Following reduction, the fracture was stabilized by below elbow cast immobilization for a period ranging between 6-8 weeks based on the post procedure radiographic evaluation.

Outcome of the conservative management was evaluated at the end of 3 months after standard physiotherapy programme. Functional evaluation was done based on Demerit point system of Gartland \& Werley with Sarmiento et al modification.

\begin{tabular}{|c|c|}
\hline End Result Point Ranges & \\
\hline Excellent & $0-2$ \\
Good & $3-8$ \\
Fair & $10-20$ \\
Poor & 21 above \\
\hline *Objective evaluation is based on the following \\
ROMis being minimum for normal function, \\
dorsiflexion-450, Palmar flexion-30, \\
Radial deviation-150, Ulnar deviation-150, \\
Pronation-50, Supination-50, \\
DRUJ-Distal radio ulnar joint. \\
\hline
\end{tabular}

\section{ANALYSIS:}

MODE OF INJURY:The most common mode of injury leading to a distal radius fracture in the study population was fall (76\%). The next common cause was road traffic accidents (18\%). Fall from height caused Colle's fracture in $2(2 \%)$ 
patients. $3(3 \%)$ patients had distal radius fracture as a result of assault and $1(1 \%)$ patient had the fracture as a result of collision with a pole.

\begin{tabular}{|c|c|c|c|}
\hline Mode of injury & Males & Females & Total \\
\hline Fall & 19 & 57 & $76 \%$ \\
\hline Road traffic accidents & 8 & 10 & $18 \%$ \\
\hline Assault & 1 & 2 & $3 \%$ \\
\hline Fall from height & - & 2 & $2 \%$ \\
\hline Collision with pole & 1 & - & $1 \%$ \\
\hline Total & $\mathbf{2 9}$ & $\mathbf{7 1}$ & $\mathbf{1 0 0}$ \\
\hline \multicolumn{2}{|c}{ Table 3: Mode of Injury } \\
\hline
\end{tabular}

COMPLICATIONS:Out of the 100 patients in the study, $57(57 \%)$ patients had complications. Out of the 57 patients, $17(29.8 \%)$ had Malunion, $13(22.8 \%)$ patients had dorsal displacement, $8(14 \%)$ patients had DRUJ associated with malunion, $7(12.3 \%)$ patients had Neurological complications, $6(10.5 \%)$ patients had palmar displacement, $4(7.1 \%)$ patients had Ulnar side wrist pain and $2(3.5 \%)$ patients had tendon injuries. Out of the 7 patients with neurological complications, 4(57.2\%) patients had Carpal tunnel syndrome and the remaining $3(42.8 \%)$ patients had Chronic regional pain syndrome.

\begin{tabular}{|c|c|c|}
\hline Complication & $\begin{array}{c}\text { No. of } \\
\text { Patients }\end{array}$ & $\begin{array}{c}\text { Percentage } \\
\text { involved }\end{array}$ \\
\hline Malunion & 17 & $29.8 \%$ \\
\hline Dorsal displacement & 13 & $22.8 \%$ \\
\hline DRUJ associated with malunions & 8 & $14 \%$ \\
\hline Neurological complications & 7 & $12.3 \%$ \\
\hline Palmar displacement (MU) & 6 & $10.5 \%$ \\
\hline Ulnar side writ pain & 4 & $7.1 \%$ \\
\hline Tendon injuries & 2 & $3.5 \%$ \\
\hline Total & 57 & 100 \\
\hline
\end{tabular}

OUTCOME: $12(12 \%)$ patients had excellent outcome, $9(75 \%)$ of them being females. $39 \%$ had good outcome and $41 \%$ had fair outcome as calculated by the Demerit point system of Gartland \& Werley with Sarmiento et al modification. 8\% of the patients had poor outcome, where $5(62.5 \%)$ of them were males.

\begin{tabular}{|c|c|c|c|}
\hline Outcome & Males & Females & Total \\
\hline Excellent & 3 & 9 & $12 \%$ \\
\hline Good & 10 & 29 & $39 \%$ \\
\hline Fair & 11 & 30 & $41 \%$ \\
\hline Poor & 5 & 3 & $8 \%$ \\
\hline Total & $\mathbf{2 9}$ & $\mathbf{7 1}$ & $\mathbf{1 0 0}$ \\
\hline \multicolumn{4}{|l}{ Table 5: Outcome of Conservative Management } \\
\hline
\end{tabular}

DISCUSSION: A total of 100 cases of distal radius fractures treated by conservatively by closed manipulative reduction and cast immobilization were included in this study. The demographic characteristics and etiological factors for the fracture were recorded. These cases were followed for a period of three months. Patients above forty years of age were included in this study. The criteria for patient selection ensured common aetiology of aging bone that resulted in fracture in most of the patients. The main reason for including patients above this age group is to consolidate the common etiological factor of degenerating bone (Low quality of bone) predisposing to fracture even after a trivial trauma.

The bulk of presentation of distal radius fractures was between $50-70$ years of age. 64\% (64) of our cases were ranging in the age group between $50-70$ years. Of these $36 \%$ were between $50-59$ years and $28 \%$ were between the age of 60-69 years.The mean age of presentation in our study population was 55 years, slightly lower than in the previous studies.Current data suggest that distal radius fractures in the elderly may represent an insufficiency fracture associated with all of the risk factors for osteoporosis. ${ }^{[5]}$

In our study there was a female sex preponderance of occurrence of distal radius fractures similar to previous studies. Decreased bone mineral density, female gender, ethnicity, heredity, and early menopause have all been demonstrated to be risk factors for this injury.[6] there is evidence to suggest a higher mortality rate following distal radius fractures, particularly in elderly males.[7] Finally, displacement following closed treatment is a predictor of instability \& repeat manipulation is unlikely to result in a successful radiographic outcome.[8,9,10] The optimal position of immobilization of the radioulnar joint is controversial, although immobilization in supination has been proposed.[11]

Of the one hundred patients treated 54\% had involvement of left upper extremity, while $46 \%$ had right upper extremity involvement indicating non dominant hand predominance. The most common mode of injury that landed the patient with distal radius fracture was fall on outstretched hand. The more common places where such falls occurred were bathroom, at or near home and less commonly at work place. The trivial nature of trauma involved in most of the cases indicates the poor quality of bone that predisposes to the occurrence of distal radius fractures in the present study population.

Perhaps the female preponderance is an indicator of the oestrogen withdrawal related bone weakening in females that resulted in higher incidence in them when compared to their opposite sex in the similar age groups.A significant percentage of study group did present with complications like mal union, Sudeck's osteodystrophy, stiffness of fingers and joints, neurological and tendon injuries. Of these, the most common complication noted was mal union which occurred in $17 \%$ of the study group.

of the one hundred patient treated by conservative means $12(12 \%)$ of patients showed excellent results, $39 \%$ showed good results, in $41 \%$ of them the outcome was fair and the remaining $8 \%$ patients showed poor results. The functional outcome in these patients was evaluated using the demerit functional scoring system.

\begin{tabular}{|c|c|c|c|c|}
\hline Study & \multicolumn{3}{|c|}{ Outcome } \\
\hline & Excellent & Good & Fair & Poor \\
\hline Altissimi etal & $38 \%$ & $49 \%$ & $11.5 \%$ & $1.5 \%$ \\
\hline Present Study & $12 \%$ & $39 \%$ & $41 \%$ & $8 \%$ \\
\hline
\end{tabular}

Table 8: Outcome of Conservative Management in the study population

All the cases were followed up for a period of three months. In most of the cases the results were in correlation with the severity of fracture based on the AO classification 
system the end result was a clear reflection of this fact that gross displacement and comminution do affect the prognosis of distal radius fractures. Because multiple variables influence the results of treatment of these injuries, definitive conclusions about such treatment and factors affecting the outcome are difficult to reach. Several studies clearly showed that restoration of the radial length is the most important factor in achieving a good end result.

The results of this study indicated that most of the elderly patients with moderate radial shortening and dorsal angulations obtained satisfactory functional outcome and did not show a significant correlation between functional outcome and anatomical outcome.

At the end of the study we conclude that conservative management of closed manipulative reduction and cast immobilization for treating extra articular distal radius fracture can be a viable option (Is a good modality of treatment) if the selection of cases is made appropriately.

CONCLUSION: The present study concerned with extra articular type of distal radius fractures managed conservatively by closed manipulative reduction and cast immobilization. The study was carried out between September 2010 to August 2012 at King George Hospital and has drawn the following conclusions.

Better results were produced in undisplaced and minimally displaced fractures (23 A 2.1 \& 2.2) treated conservatively by closed manipulative reduction and cast immobilization. However as the degree of displacement increased results obtained were not satisfactory. Gross displacement and comminution (23 A 3.1, 3.2 \& 3.3) were associated with poor results even though accurate reduction was obtained during manipulation. These cases required repeated manipulation and the reduction was not maintained even after proper application of the cast.

Hence it may be concluded that conservative management still holds good for undisplaced and minimally displaced fractures (23 A 2.1 \& 2.2) However in fracture of distal radius with significant displacement and comminution especially if the quality of bone is not good, it is difficult to obtain good functional outcome through conservative management alone.

\section{BIBLIOGRAPHY:}

1. Colles A. On the Fracture of the carpal extremity of the radius. Edinburgh Med Surg 1814; 10: 182-186.

2. Joseph Schatzker - Marvin Tile-The Rationale of Operative Fracture Care Third Edition 2005.

3. Hagino $\mathrm{H}$, Yamamoto $\mathrm{K}$, Ohshiro $\mathrm{H}$, et al. Changing incidence of hip, distal radius, and proximal humerus fractures in Tottori Prefecture, Japan. Bone 1999; 24: 265 270.

4. Solgaard S, Petersen VS. Epidemiology of distal radius fractures. Acta Orthop Scand 1985; 56: 391-393.
5. Mensforth RP, Latimer BM. Hamann-Todd Collection aging studies: osteoporosis fracture syndrome. Am J Phys Anthropol 1989; 80: 461-479.

6. Lester GE, Anderson JJ, Tylavsky FA, et al. Update on the use of distal radial bone density measurements in prediction of hip and Colles' fracture risk. J Orthop Res 1990; 8: 220-226.

7. Rozental TD, Branas CC, Bozentka DJ, et al. Survival among elderly patients after fractures of the distal radius. J Hand Surg Am 2002; 27: 948-952.

8. Flinkkilä T, Ristiniemi J, Hyvönen P, et al. Nonbridging external fixation in the Treatment of unstable fractures of the distal forearm. Arch Orthop Trauma Surg 2003;123: 349-352.

9. Leung F, Ozkan M, Chow SP. Conservative treatment of intra-articular fractures of the distal radius-factors affecting functional outcome. Hand Surg 2000; 5: 145 153.

10. McQueen MM, Hajducka C, Court-Brown C. Redisplaced unstable fractures of the distal radius: A randomised, prospective study of bridging versus non-bridging external fixation. J Bone Joint Surg Br 1996; 78: 404-409.

11. Solgaard S, Bunger C, Sllund K. Displaced distal radius fractures. A comparative study of early results following external fixation, functional bracing in supination, or dorsal plaster immobilization. Arch Orthop Trauma Surg 1990; 109: 34-38.
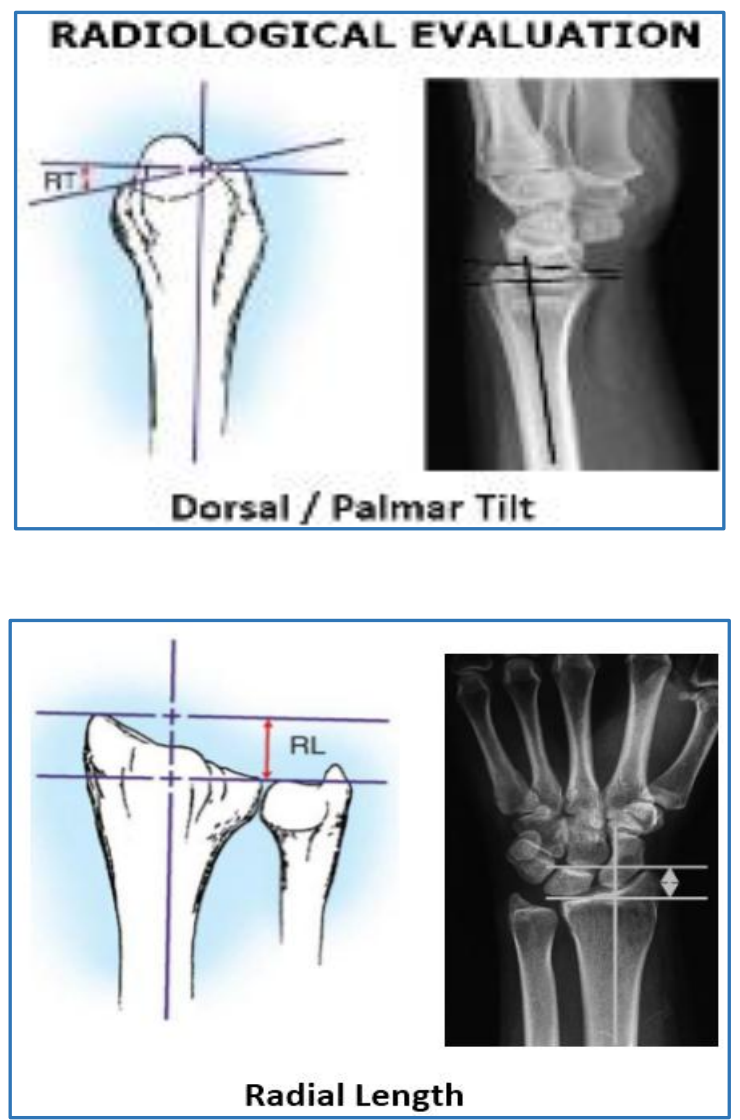

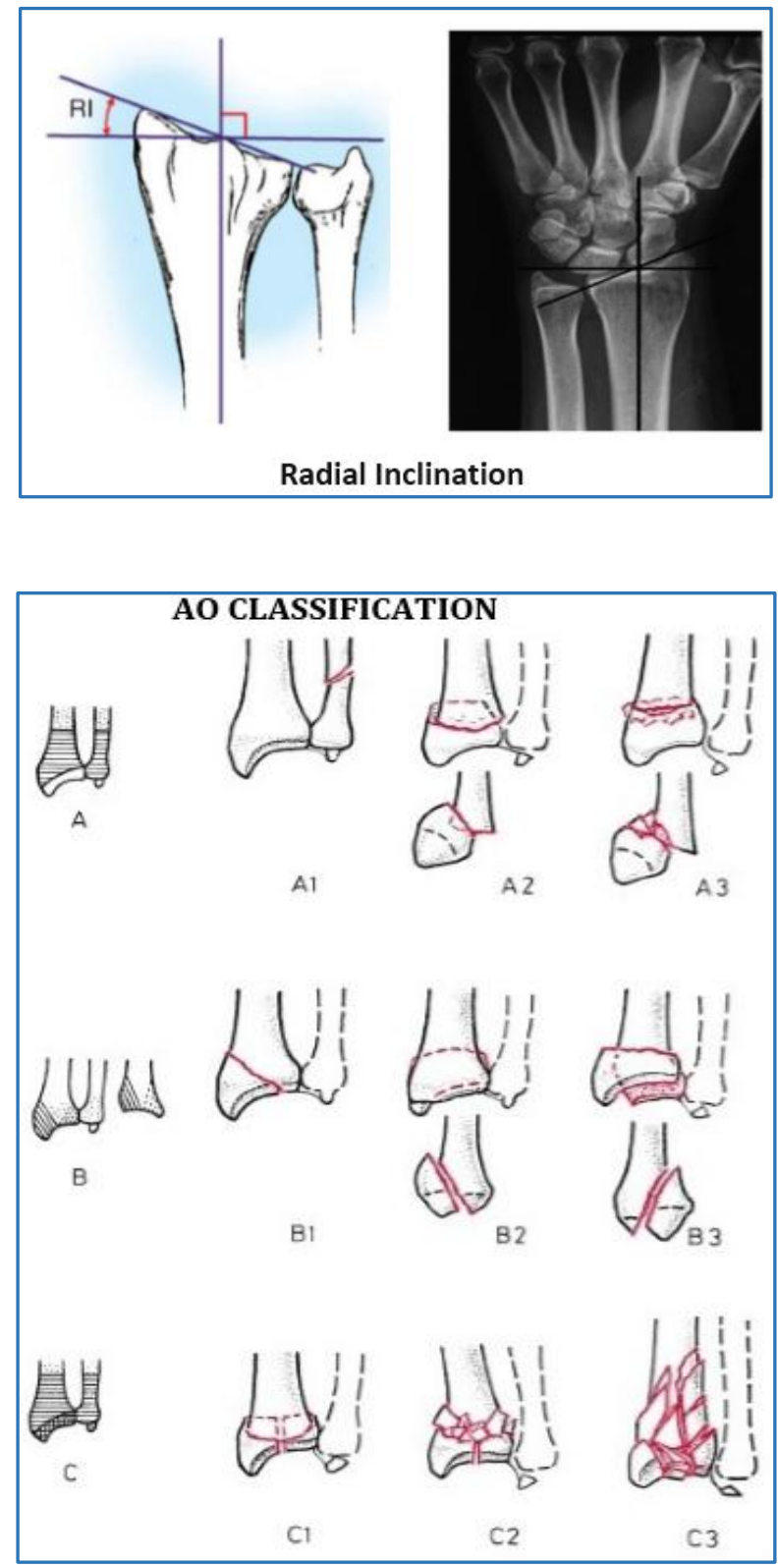

\section{CASTING TECHNIQUE}

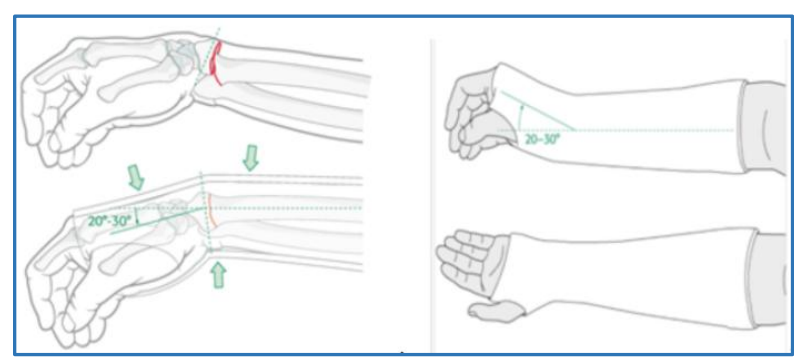

The application of 3-point moulding of the cast, as shown, will serve to resist late redisplacement. The wrist should be placed in $20-30^{\circ}$ of flexion, $15^{\circ}$ ulnar deviation and $20^{\circ}$ pronation. To prevent instability, ensure that there is no overlapping of the volar cortex. Adequate contact of the cortical surface of each fragment increases stability
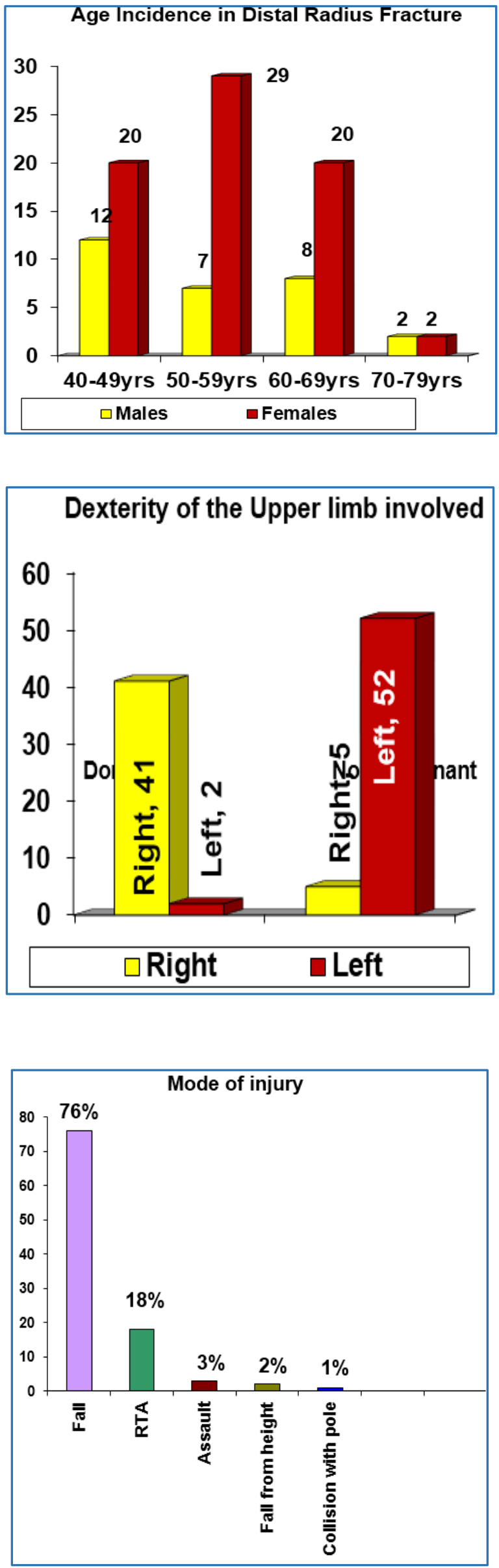

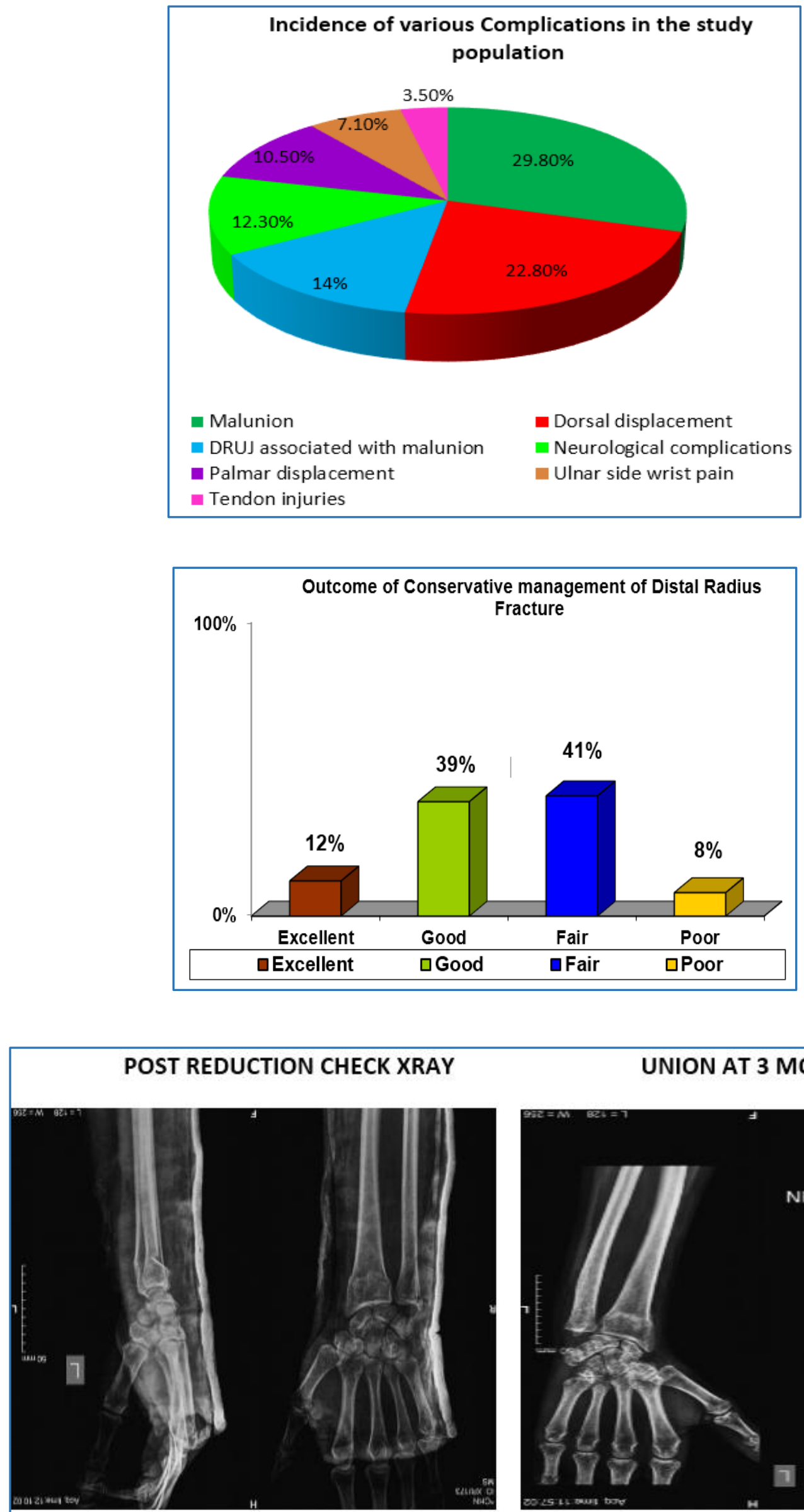

UNION AT 3 MONTHS

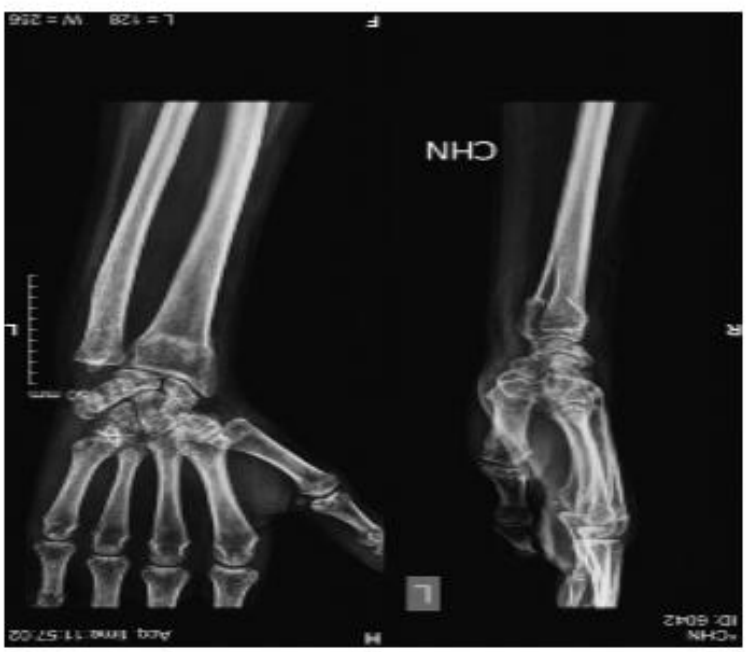



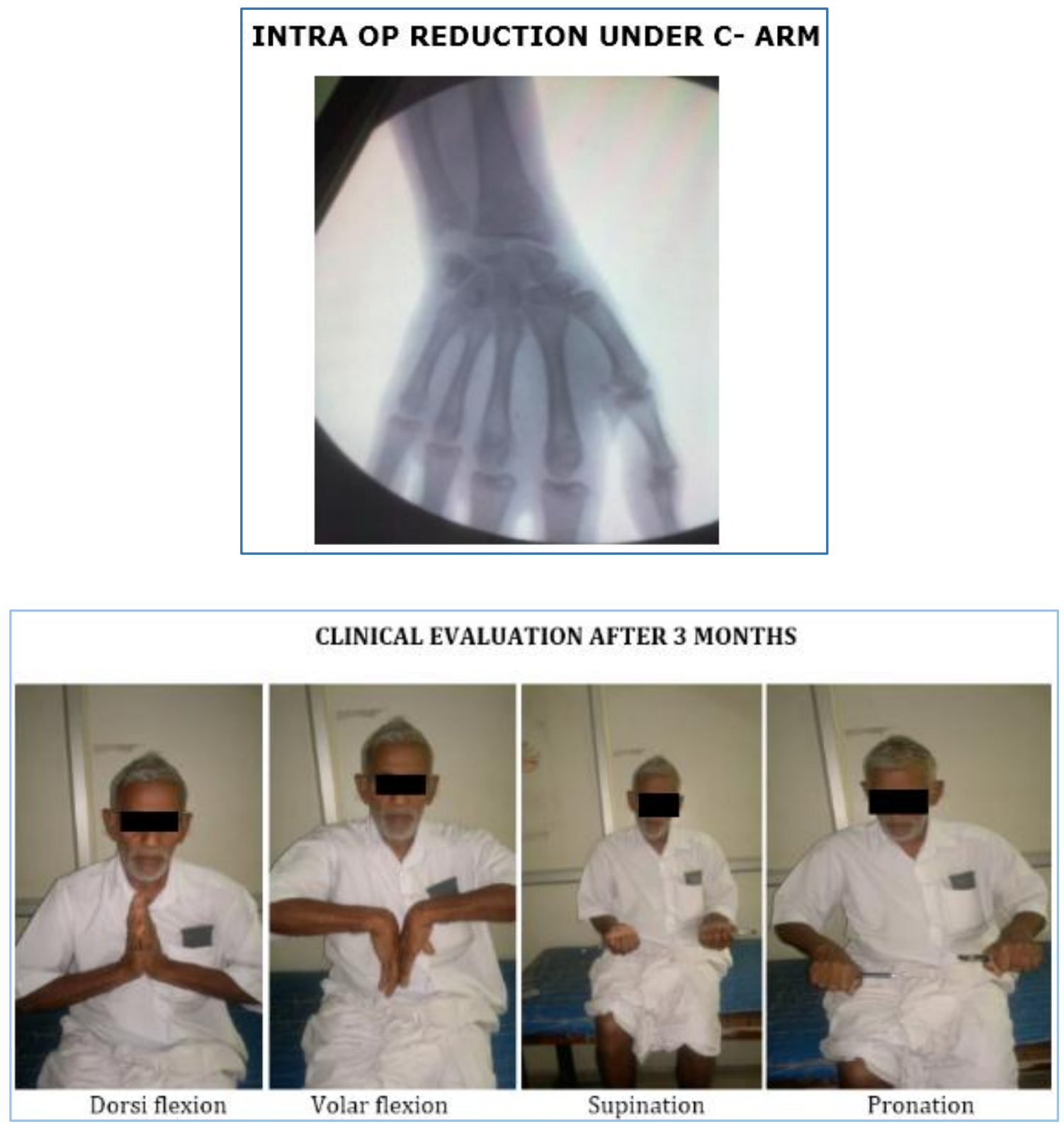